\title{
Spatial genetic pattern in an economically beneficial insect, the cyclical African wild silk moth (Gonometa postica)
}

\author{
Timothy C. Bray* \\ Department of Zoology and Entomology, University of Pretoria, Hatfield, 0028 South Africa \\ Received 12 September 2013. Accepted 22 January 2014
}

\begin{abstract}
The African wild silk moth (Gonometa postica) exhibits large inter-annual population size fluctuations in the Kalahari region of southern Africa. Spent cocoons from this species are currently being utilized in a local silk industry. An understanding of the recolonization dynamics of a particular harvested site, and of the population genetic effects of such dispersal, are crucial for designing a scientifically-based harvesting strategy. I link morphological estimates of flying ability to microsatellite genotyping in the determination of dispersal ability of this species. Morphological results suggest that the moth is a poor disperser with high wing loadings and males are better fliers than females. There is a significant effect of isolation-bydistance. Spatial population genetic analyses of microsatellite data further indicate lower and upper bounds on dispersal of $90 \mathrm{~m}$ and $50 \mathrm{~km}$. The combined evidence suggests male-biased dispersal over several dozen kilometers with females that do not disperse over large distances. I discuss the potential influences of large population size fluctuations on patterns of genetic diversity and the implications for the inference of dispersal in my study species.
\end{abstract}

Key words: isolation by distance, Lepidoptera, microsatellites, population cycles, spatial autocorrelation.

\section{INTRODUCTION}

Many species exhibit complex population cycles and large fluctuations in both density and population size (Bjornstad et al. 2002; Turchin 2003; Kapeller et al. 2011). Turchin (2003) reviewed the dynamics of such complex population cycles and concluded that they are the result of the interaction between endogenous as well as exogenous factors that encompass environmental effects, including climatic, population-specific (e.g. density dependence), and inter-specific interactions such as predator-prey relationships. Although the ecological literature of complex population cycles is extensive, comparatively few genetic studies have been conducted on such species. Population genetic studies on cyclical species have the potential to provide information on dispersal, variability of subpopulations, and the effects of the underlying landscape on dispersal and shaping population genetic structure (e.g. Berthier et al. 2005).

Population genetic analyses may be complicated by the effects of population cycles on spatial genetic patterns. Increased population sub-structuring may be expected in species that exhibit population cycles (Wright 1940), due to increased probability of allele fixation by genetic drift in the resultant

*E-mail: tim_c_bray@hotmail.com small populations. On the one hand such effects of extinction and recolonization on spatial genetic pattern have been evaluated for species with a metapopulation structure (Ibrahim 2001; Orsini et al. 2008). The effect of such population turnover on genetic differentiation is dependent on the number of individuals colonizing a deme relative to the number of recurrent migrants between demes (Whitlock \& McCauley 1990; Ibrahim 2001). This is intuitive for metapopulations, since low numbers of founders are likely to produce greater genetic structure, as is colonisation from single versus multiple demes. On the other hand recurrent migration tends to homogenize genetic diversity. However, some species do not have obvious metapopulation structure and simply exist as continuous populations where neighbourhood sizes fluctuate as a result of local changes in density. Dispersal in these instances approach a continuously distributed isolation by distance (IBD) model (Wright 1943) and genetic diversity may be homogenized across the range of the species, dependent on dispersal and population size fluctuations (Slatkin 1993).

The African wild silk moth (Gonometa postica) is a continuously distributed species with marked local population cycles in the dry savanna of the Kalahari region of southern Africa (Veldman 2004). 


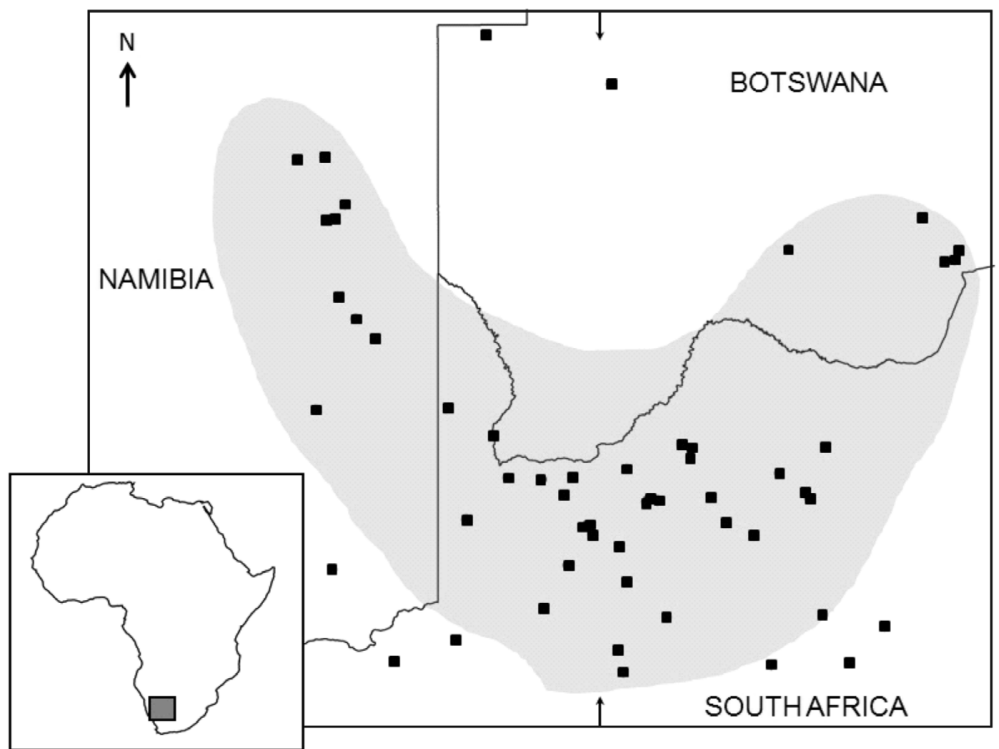

Fig. 1. Distribution of Gonometa postica in southern Africa with sampling localities across Namibia, Botswana, and South Africa. The distribution of eruptive populations is depicted as a grey polygon and sampling locations as squares.

The species has two generations per year, the first starting in September-October when moths emerge from cocoons. Moths emerge without feeding mouthparts and survive for three to five days (maximum nine days, Hartland-Rowe 1992) during which breeding occurs. Eggs are laid, larvae emerge and pass through six instar larval stages in approximately five weeks, after which the larvae construct cocoons, pupate and enter diapause that either carries through to the following September when adults emerge, or is broken in February when an additional population cycle occurs. Typically, this second generation comprises between 12 and $50 \%$ of the numbers seen in the first generation (Hartland-Rowe 1992), and culminates in pupae that emerge as adults in September. G. postica experiences large inter-annual population size fluctuations (Veldtman 2004) In addition to the temporal cyclical nature of the species, both spatial abundance (Delport 2005) and female fecundity (Ngoka et al. 2007) can vary widely even within a season. Cocoons from this species are currently being utilized in an African Wild Silk Industry (e.g. Steyn \& Olivier 2010) and this study attempts to contribute towards a better understanding of the spatial dispersion of these moths, crucial for the sustainable harvesting of African wild silk. The purpose of this article is twofold. Firstly, I infer the dispersal ability of the species using morphological and molecular methods, and secondly I investigate the potential effects of population cycles and spatial variance in abundance of G. postica on the spatial genetic structure in this species.

\section{METHODS}

\section{Study site}

Gonometa postica is an eruptive species that is common in the Kalahari region of southern Africa (Fig. 1). Although the species has been recorded in other areas (e.g. Ngoka et al. 2007), the Northern Cape Province of South Africa and Kalahari region are considered the core region in southern Africa (Veldtman et al. 2002), where the species is regularly recorded in large numbers. Microsatellite data were collected from 52 localities in this area (Fig. 1).

\section{Morphological data}

I collected pupae from trees during June 2002. Adult moths were then allowed to emerge in the laboratory and were frozen at $-20^{\circ} \mathrm{C}$. I estimated a measure of dispersal ability based on wing load (i.e. the ratio of body mass to total wing area), previously used as a proxy for estimating dispersal or flying ability of Lepidoptera (Casey \& Joos 1983). I pinned and photographed one fore- and one hind wing from each of 153 individuals (57 males, 96 females) at two megapixel resolution with a FujiFilm FinePix S304 digital camera at 
constant height. Eight calibration photographs were taken at random intervals during the course of digitizing wings. Total wet body mass was measured, using a Scaltec Sac51 digital scale, before removal of wings. Dry mass was not determined since the moths were frozen at $-20^{\circ} \mathrm{C}$ for subsequent DNA extraction and analyses. The sexes of the moths were easily scored due to their large sexual size dimorphism (Veldtman et al. 2002). Total wing area was measured from digitized images. Images (JPEG format) were first converted to grayscale images in ImageJ (Rasband 1997) and wing areas were measured with the particle analysis tool (where all particles greater than 10000 pixels were analysed). Scale (in mm) was set from calibration images.

\section{Genetic sampling and laboratory methods}

Total genomic DNA was extracted from 220 individuals collected, using a Qiagen DNeasy extraction kit. All individuals were genotyped for six polymorphic microsatellite loci (Gon6, Gon60, Gon65, Gon55, Gon107, Gon120). Protocols for microsatellite development and amplification conditions are described in Delport et al. (2005).

\section{Statistical genetics methods}

Microsatellite data were evaluated for linkage disequilibrium, evaluating the non-random association of alleles at different loci (Black \& Krafsur 1985) in GENETIX (Belkhir et al. 2004). Deviations from Hardy-Weinberg equilibrium were calculated from allelic count data using an analogous method to that of Fisher's exact test, applied using GENEPOPv4 software (Rousset 2008). Summary statistics for genetic variation were compiled, as well as an analysis for the presence of null alleles (Kalinowski \& Taper 2006) and a test for potential population expansion or contraction using the multi-sample score test (Rousset \& Raymond (1995), both through GENEPOP v4. I additionally applied a method of resolution assessment for the set of marker loci chosen using GENCLONE (Arnaud-Haond \& Belkhir 2007).

Further analyses were based on a continuous population with IBD model, where the probability of identity in state between two neutral genes decreases with the geographic distance between them (Wright 1943, 1969). This model is most suitable when analysing data from species that are continuously distributed, or where demes or subpopulations cannot be easily demarcated. The analyses were subdivided into three approaches: (i) spatial autocorrelation statistics, (ii) spatial regression statistics, and (iii) hierarchical F-statistics. Although the calculation of $F$-statistics does not assume an IBD model per se, the method of the sequential pooling of individuals into populations allows the inference of the scale at which populations may be structured.

(i) Spatial autocorrelation statistics: spatial autocorrelation methods were used to assess the spatial distribution of allelic frequencies among localities. Spatial autocorrelation methods typically involve the calculation of some spatial statistic, such as Moran's I (Sokal \& Oden 1978; Epperson and Li 1996) at successive distance intervals. Theoretically, a decrease in the statistic with distance is indicative of the degree of IBD (Hardy \& Vekemans 1999; Diniz-Filho \& Telles 2002). Since the choice of distance intervals can bias the interpretation of results in the spatial analyses (Fenster et al. 2003), Hardy \& Vekemans (2003) have suggested the use of two statistics that prevent this potential bias. The $\%$ partic is the proportion of all individuals represented at least once in the particular distance interval, whereas the $\mathrm{CV}$ partic is the coefficient of variation of the number of times each individual is represented in the distance interval (Hardy \& Vekemans 2003). As a rule of thumb the $\%$ partic should be greater than $50 \%$ and the $\mathrm{CV}$ partic less than or equal to 1 for each distance interval. I evaluated alternate distance intervals and chose the set which satisfied these conditions (Table 1). Spatial autocorrelation statistics were calculated for each of the above distance classes using SPAGeDi (Hardy \& Vekemans 2003) and the relationship between spatial autocorrelation coefficients and distance (correlograms) was plotted to investigate IBD.

(ii) Spatial regression statistics: the spatial regression of genetic distance with geographic distance was used to estimate neighborhood size $(\mathrm{Nb})$. Rousset's (1997) multilocus estimator of an FST/(1-FST) Between populations, was plotted against the natural logarithm $(l n)$ of geographical distance, and regression statistics calculated. I used a population-based statistic over an individualbased statistic (Rousset 2000) since I had sampled multiple individuals from single trees. An individual-based approach (Rousset 2000) would require the exclusion of data where more than one individual was sampled at a particular tree, and thus I treated individual trees as populations, and included populations located 1 to $500 \mathrm{~km}$ apart with more than three individuals. I calculated 
Table 1. Statistics for the optimal distance classes chosen for spatial correlogram analysis. 'Maximum distance' is the upper bound of each distance class, 'Number of pairs' is the number of pairwise comparisons within the distance class. '\% partic' and ' $\mathrm{CV}$ partic' are indications of the proportion of all individuals utilized to calculate the statistics of interest within each distance class.

\begin{tabular}{lcccccccccc}
\hline Distance class & 1 & 2 & 3 & 4 & 5 & 6 & 7 & 8 & 9 & 10 \\
\hline Maximum distance $(\mathrm{km})$ & 1 & 100 & 150 & 210 & 270 & 320 & 410 & 500 & 570 & 680 \\
Number of pairs & 384 & 2376 & 2365 & 2375 & 2379 & 2374 & 2357 & 2392 & 2357 & 2363 \\
\% partic & 88 & 92.7 & 85.9 & 100 & 92.7 & 100 & 100 & 100 & 100 & 96.8 \\
CV partic & 0.65 & 0.7 & 0.84 & 0.73 & 0.78 & 0.72 & 0.59 & 0.74 & 0.72 & 0.87 \\
\hline
\end{tabular}

multi-locus estimates of pairwise differentiation, regressed against the natural logarithm of geographic distance and tested the significance of the observed correlation between genetic and geographic distances with a randomized permutation procedure (10 000 permutations). $P$-values were estimated as the proportion of the permuted regression values greater than that observed, and thus indicative of greater IBD. Neighborhood size was calculated as the inverse of the slope of this regression. All spatial regression analyses were performed with GENEPOP v4.0 (Rousset 2008).

(iii) Hierarchical F-statistics: I performed hierarchical F-statistics (Goudet et al. 1994), comprising the sequential pooling of individuals into populations by increasing the geographical extent of each population at each subsequent level, until all individuals are included as a single population. At each level, F-statistics are calculated and plotted against the level of pooling. Although the method used to pool individuals is subjective, pooling on the basis of geographic distance is acceptable (Goudet et al. 1994). I used five levels for the calculation of F-statistics, namely within 5, 10 50, 100 , and $200 \mathrm{~km}$. For each pooling level, adjacent populations within the specified distance of one another were combined as a single population. Weir \& Cockerham's (1984) theta (FST) and FIS, were calculated using custom software for each sequential grouping, and 95\% confidence intervals were obtained by bootstrapping over loci.

\section{RESULTS}

\section{Morphological results}

Consistent with the size dimorphism results of Veldtman et al. (2002) I detected significant differences between male and female body mass, hind wing area, front wing area and total wing area (Table 2). Females are approximately six times heavier than males, yet have only an estimated four times greater wing surface area. This result translates into a significantly higher wing load for females, than for males (Table 2).

\section{General statistics}

Moderate to high levels of genetic variation were seen with allele numbers varying from four to 21 per locus (Appendix 1). Three of the loci (Gon60, Gon65, Gon120) significantly deviated from Hardy-Weinberg Equilibrium $(P<0.001)$ (Appendix 1). Five locus pairs demonstrated significant inter-locus allelic linkage after a sequential Bonferroni correction for multiple tests (Table 3). A heterozygote deficiency $(P \leq 0.001)$ was demonstrated in the investigation of any signal of recent

Table 2. Indirect morphological estimates of dispersal ability in Gonometa postica. Mass, hind wing, forewing and total wing areas are shown, as is the wing load (the ratio of body mass to total wing area). The $P$-value reflects the results of a $t$-test, for unequal sample sizes, of the difference in means between male and female morphological characteristics.

\begin{tabular}{|c|c|c|c|c|c|}
\hline & \multicolumn{2}{|c|}{ Male } & \multicolumn{2}{|c|}{ Female } & \multirow[t]{2}{*}{$P$} \\
\hline & Mean & S.D. & Mean & S.D. & \\
\hline Mass (g) & 0.533 & 0.111 & 2.97 & 0.65 & $<0.001$ \\
\hline Hind wing area $\left(\mathrm{mm}^{2}\right)$ & 63.0 & 12.8 & 268.4 & 52.6 & $<0.001$ \\
\hline Forewing area $\left(\mathrm{mm}^{2}\right)$ & 124.9 & 20.8 & 446.5 & 85.4 & $<0.001$ \\
\hline Total wing area $\left(\mathrm{mm}^{2}\right)$ & 187.9 & 32.8 & 714.8 & 136.2 & $<0.001$ \\
\hline Wing load $\left(\mathrm{g} / \mathrm{mm}^{2}\right)$ & 0.003 & 0.001 & 0.004 & 0.001 & $<0.001$ \\
\hline Wing load $\left(\mathrm{N} / \mathrm{m}^{2}\right)$ & 28.6 & 7.6 & 41.2 & 8.3 & \\
\hline
\end{tabular}


Table 3. Proportion of linked alleles between locus pairs with the probability of an association below the diagonal $\left(P=0.001,0.01,0.05\right.$ and not significant, ${ }^{\star \star *},{ }^{\star *},{ }^{*}$, N.S. $)$.

\begin{tabular}{|c|c|c|c|c|c|c|}
\hline & Gon6 & Gon60 & Gon65 & Gon55 & Gon107 & Gon120 \\
\hline Gon6 & & 0.08 & 0.06 & 0.25 & 0.04 & 0.00 \\
\hline Gon60 & NS & & 0.10 & 0.00 & 0.06 & 0.21 \\
\hline Gon65 & * & $\star \star \star *$ & & 0.02 & 0.03 & 0.05 \\
\hline Gon55 & NS & NS & NS & & 0.04 & 0.07 \\
\hline Gon107 & NS & * & NS & NS & & 0.03 \\
\hline Gon120 & NS & $* * *$ & $* * *$ & NS & NS & \\
\hline
\end{tabular}

population expansion (data not shown). Potentially significant frequencies of null alleles (i.e. $=$ 0.2; Dakin \& Avise 2004) were detected across three of the loci (Gon6, Gon60, and Gon65; Appendix 1). Five loci were required to attain a mean of $95 \%$ unique multilocus genotypes, inclusive of missing data (Fig. 2).

\section{Statistical genetics methods}

\section{Spatial autocorrelation}

Plotting spatial autocorrelation statistics (Moran's I (M), Loiselle's statistic (L), and Ritland's R) against increasing geographic distance yielded a negative slope, giving a weak indication of IBD (Fig. 3). However, permutation tests of the regression of spatial statistics against $l n$ distance indicate that combined-locus correlograms do not indicate a significant association of spatial statistics with distance.

\section{Spatial regression}

In this case 33 populations were represented (location information; Appendix 2), with an average of 5.2 individuals per population. A Mantel test of FST/(1-FST) against geographic distance (Fig. 5) indicated a statistically significant correlation between distance and genetic differences (10000 permutations; $P<0.01$ ). Moreover, the regression analysis of pairwise FST/(1-FST) against geographic distance yielded a positive relationship (results not shown, correlation coefficient $=$ 0.005). Permutation tests determined that the probability of a random correlation between geographic and genetic distances greater than that observed, was significantly low $(P=0.043)$. Calculation of neighbourhood size from the slope of the regression yielded an estimate of 191 individuals. Given a demographic density estimate, and the calculated neighbourhood size, it is possible to infer dispersal (Rousset 2000). McGeoch et al. (2004) provide preliminary density estimates of 150-1075 cocoons per hectare $(0.015-0.1075$ cocoons $/ \mathrm{m}^{2}$ ). However, since $G$. postica cocoons are parasitized extensively (Veldtman et al. 2004; Fening et al. 2008b), I adjusted the density for no loss, $25 \%$ loss and $50 \%$ loss to parasitism and predation. These putative corrected densities of adults $/ \mathrm{m}^{2}$ provide a potential dispersal range of G. postica, given the observed data. The adjusted densities,

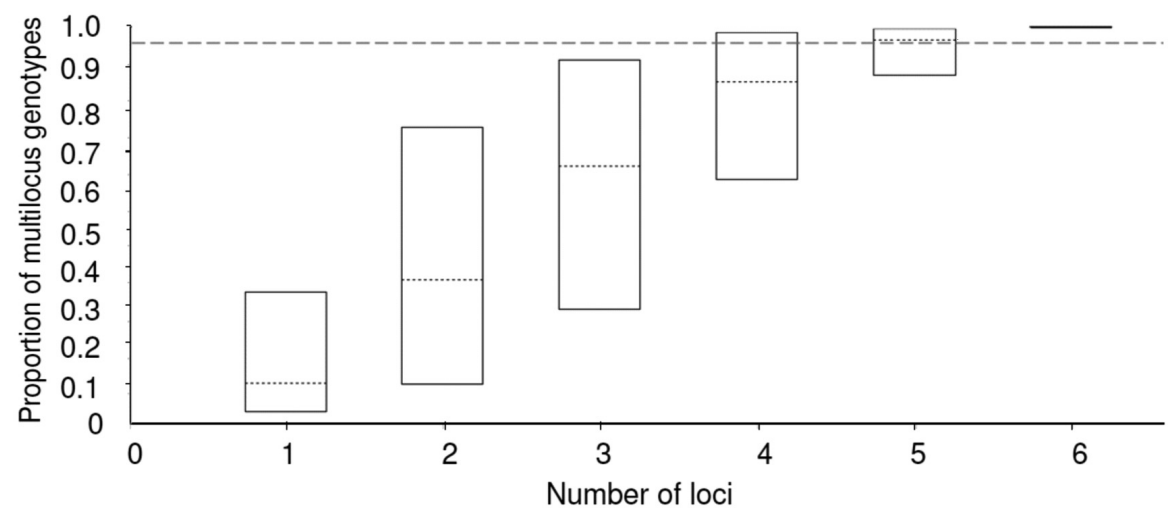

Fig. 2. Average number of unique multilocus genotypes detected over 1000 permutations for each number of loci (minimum and maximum values are included in the form of $y$-axis error bars; the $95 \%$ assignment is shown by the dashed line). 


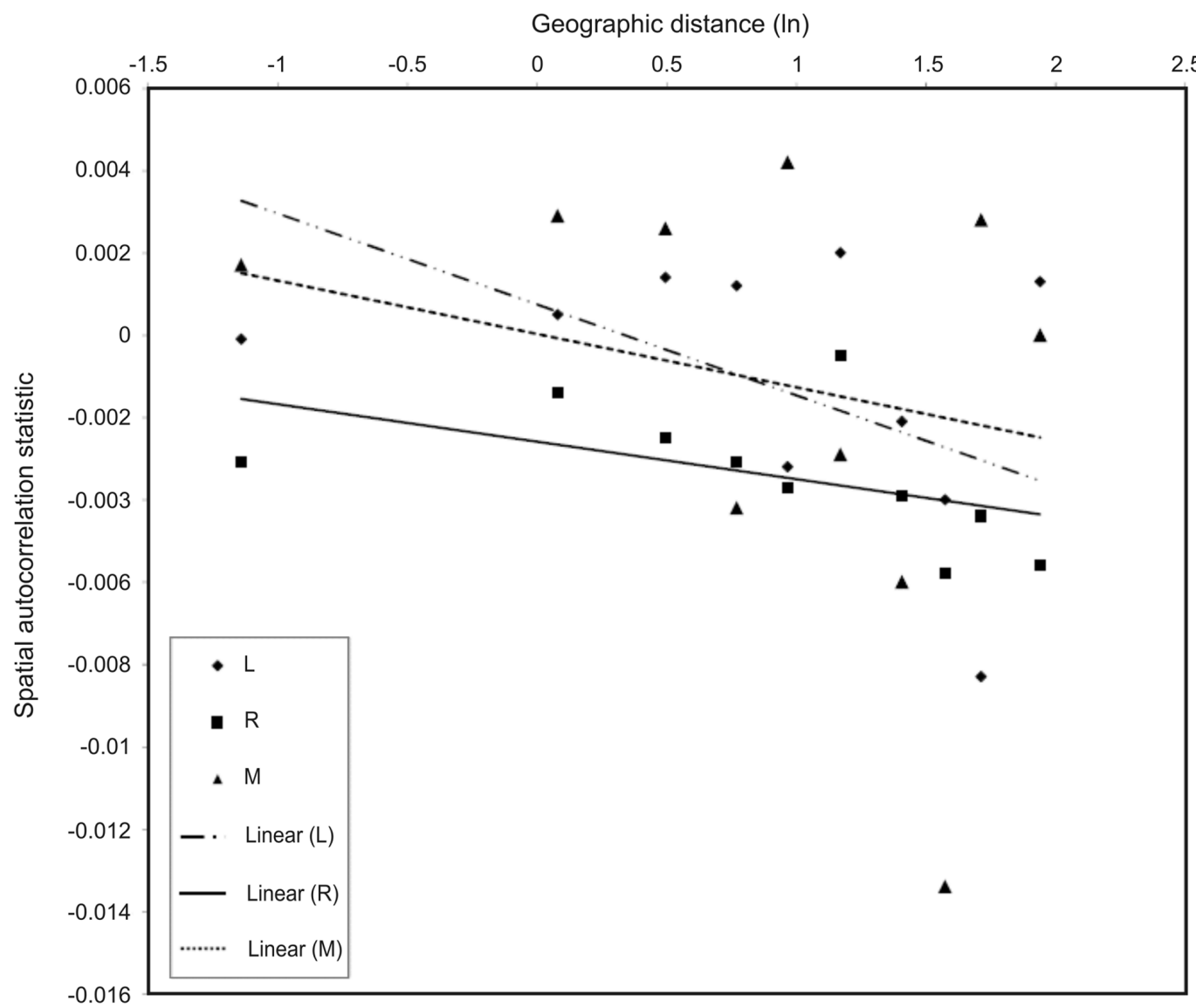

Fig. 3. Spatial autocorrelation summarized using Moran's (M), Loiselle's (L), and Ritland's (R) statistics (Sokal \& Oden 1978, Epperson \& Li 1996; Loiselle et al. 1995; Ritland 1996) averaged across loci and plotted against In distance; lines of best fit are included for each statistic. Regression coefficients for L, R, and M statistics against In distance are $-0.0013,-0.0012$, and -0.0022 , respectively.

combined with a neighbourhood size of 191 individuals, suggest a mean parent-offspring dispersal distance of between 16.8 and $90 \mathrm{~m}$. Lower density estimates (or higher parasitism/predation rates) result in correspondingly higher estimates of dispersal distances.

\section{Hierarchical F-statistics}

Hierarchical $F$-statistics indicated a slight increase in $F_{I S}$ with the successive pooling levels (not significant; data not shown). Since $F_{I S}$ is a measure of deviation from Hardy-Weinberg within subpopulations, an increase in $F_{I S}$ is expected over successive pooling levels. This result is the consequence of combining non-interbreeding subpopulations, resulting in a Wahlund effect (Wahlund 1928). In contrast, successive pooling levels show a decrease in FST (Fig. 4), markedly evident after the third level, where localities occurring within $50 \mathrm{~km}$ of one another were pooled. Since FST is a measure of genetic differentiation over subpopulations, the rapid decrease in FST at this point is indicative of where the pooling level represents an essentially panmictic population, i.e. between subpopulation genetic differentiation is pooled into a single panmictic unit.

\section{DISCUSSION}

\section{Morphological information}

The morphological indicators of dispersal ability as determined by wing loading give an indication of dispersal ability of G. postica. In Lepidoptera, there is a positive correlation between body mass and wing loading (Casey \& Joos 1983), which suggests that a lower wing load translates into more 


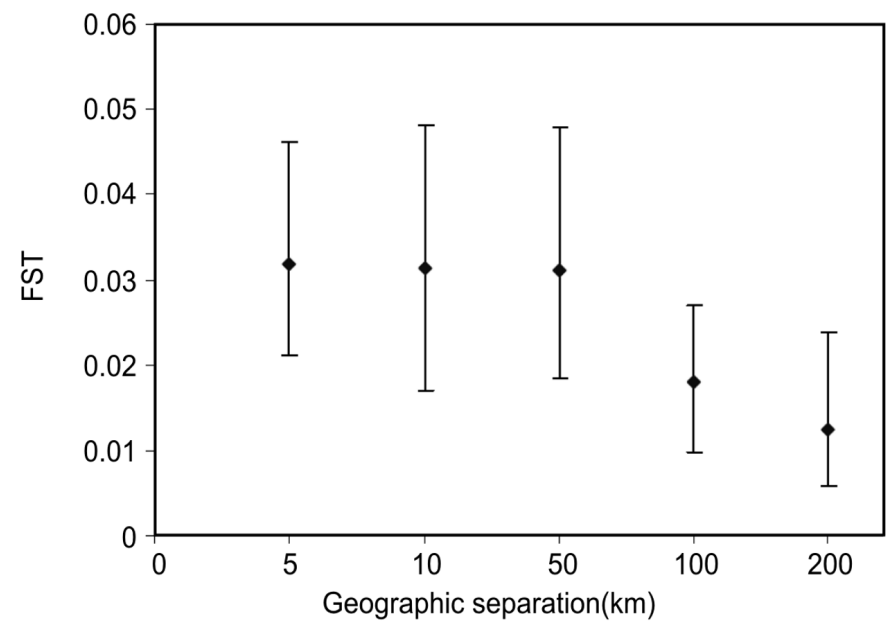

Fig. 4. Hierachical FST plotted for the successive pooling levels of 5, 10, 50, 100, and $200 \mathrm{~km}$ separation distances (including standard error around the mean).

energy-efficient flying. This relationship reflects how wing stroke frequency decreases with body size (Casey \& Joos 1983). At the extreme of wing load in moths, sphingid moths are considered the fastest flying group of insects (Matthews 1992), and known to disperse and migrate long distances (Haber \& Frankie 1989). Gonometa postica is a moth of similar mass to the sphingid tobacco hawk moth (Stevenson et al. 1995), yet has substantially higher wing load as a result of smaller wing surface area. Given such a high wing load, G. postica would need an extremely high wing stroke frequency for sustained flight, which would be energetically expensive. Efficient flying is necessary for G. postica,

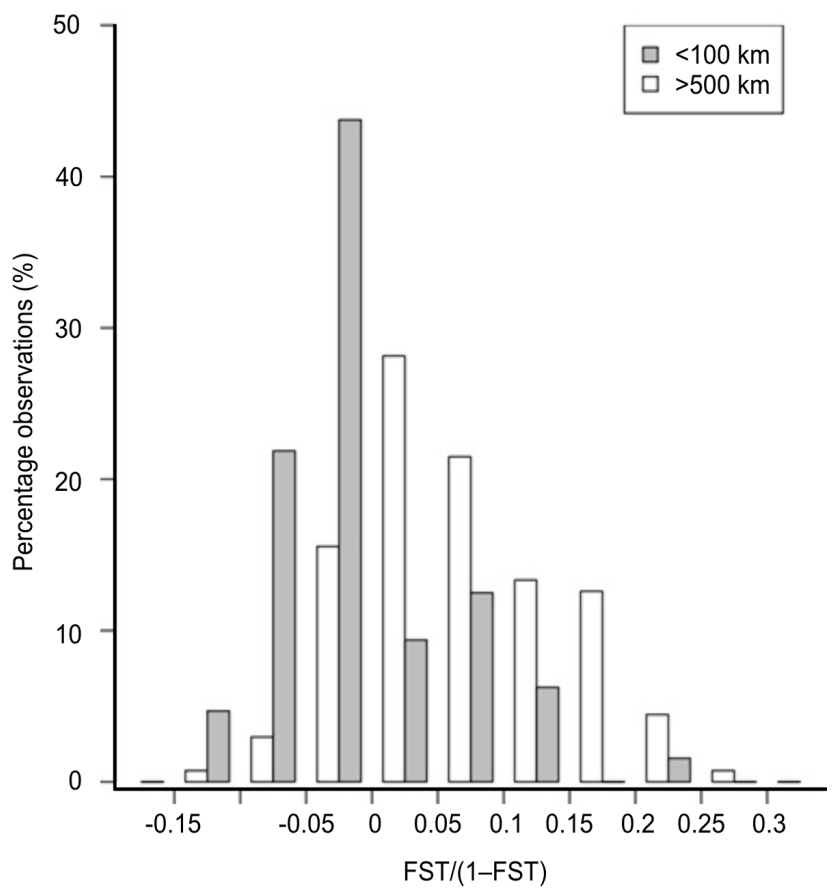

Fig. 5. Differences in the distribution of FST/(1-FST) (Roussett 1997) for closely-situated populations $(<100 \mathrm{~km}$; $n=64)$ and for distant populations (>500 km; $n=135)$, showing the small but significant differences indicated by a Mantel test as well as regression analysis. 
since the adult moths have no feeding apparatus and rely on reserves from the pupal stage to sustain flight. Species with high wing stroke frequencies have flights that are irregular and characterized by erratic movements (Rydell \& Lancaster 2000). Field observations of G. postica females at ultraviolet light traps demonstrate this behaviour (W. Delport, pers. comm.). Male G. postica demonstrate lower wing loading, and can be seen to begin warming their wings with high frequency strokes soon after emergence from the cocoon (W. Delport, pers. comm.). Rydell \& Lancaster (2000) attribute the need for warming-up flight muscles to species with higher wing loads that need to achieve a higher thoracic temperature than species with lower wing loads. Given this observed difference between male and female G. postica, females are expected to be more sedentary and males dispersive.

A wing loading is not the only factor that affects the dispersal ability of moths (Rydell et al. 1997; Waldbauer \& Sternburg 1982), other morphological indicators of dispersal ability are important. There is a notable absence in G. postica of a stabilityenhancing fulcrum and spine between the hindand forewings (W. Delport, pers. comm.). Given the high levels of variation seen in morphometric measures and their influence on dispersal ability across genera (Beck \& Kitching 2007), a key factor such as the lack of a stabilizing fulcrum is likely to lend support to the conclusion of low dispersal ability in G. postica, especially for females.

\section{Spatial genetic structuring}

The test for spatial autocorrelation of alleles with geographic distance indicated a pattern not significantly different from a random association. These results may be due in part to the inability for spatial autocorrelation statistics to incorporate potential sources of error in population genetic data (Slatkin \& Arter 1991). These authors stressed that population genetic data are characterized by three sources of variance: Sampling, stochastic, and parametric. Although these criticisms of spatial autocorrelation methods are robust, I believe the patterns observed in my data are rather the result of the failure for equilibrium of spatial genetic structure to be reached. Sokal \& Wartenberg (1983) have shown that correlograms are established within 50 generations. Furthermore, within 150 generations correlograms reach a quasi-stationary state, which persists for hundreds of generations (Epperson 1995). Given the present knowledge of strong population size fluctuations in G. postica (Veldtman \& McGeoch 2004; Fening et al. 2008a) it is unlikely that correlograms, indicative of IBD, would have reached an equilibrium state. Hierarchical F-statistic analyses showed a substantial reduction in FST values beyond a geographical extent of $50 \mathrm{~km}$, suggesting that this is the potential extent of populations or localized emergences. Spatial regression of FST against distance, however, combined with basic estimates of density, indicated a natal dispersal distance of between 17 and $90 \mathrm{~m}$. It is likely that the latter value is closer to the real minimum dispersal distance (using the lower margin for density and $50 \%$ predation), due to the estimated parasitism rate of up to 33\% (Fening et al. 2008b) and allowing for some influence of other predators (e.g. birds). Given the difference in vagility between the sexes, dispersal probably encompasses the entire range spectrum. The breeding success of just a few males at the extreme of their dispersal potential should be sufficient to lead to the decrease in FST seen past the $50 \mathrm{~km}$ boundary.

\section{Effects of reproductive variation and population cycling on spatial genetic pattern}

The theoretical expectation for the effect of population cycling on spatial genetic pattern is an increase in genetic structure as a result of local genetic drift (Wright 1940). The results presented here are inconsistent with this explanation, demonstrating little evidence of IBD. Instead, G. postica displays results more consistent with a highly stochastic spatial arrangement of explosive reproduction that prevents the establishment of a long-term pattern of spatial autocorrelation. This effect of the strong influence of a few successful broods can be seen in the distribution of genetic variation. The evidence is threefold: strong signal of a population expansion, linkage disequilibrium between alleles across loci, and high frequencies of null alleles. The signal of a population expansion signal is inferred from a heterozygote deficiency within the population, related to the respective rate of change of allele numbers of different frequencies and heterozygosity. The evidence of null alleles is inferred through the under-representation of heterozygotes when one of the two alleles fails to amplify. This deficiency of heterozygotes can be also seen as a consequence of the mixing of few reproductive events spatially. We might expect up to $10 \%$ association between alleles across loci due to segregation according to 
multiple population groups or if there were null alleles present (T. Hoareau, pers. comm.). In this case, two pairs of loci demonstrate associations between alleles of over $20 \%$, and five of the 15 pairwise combinations are significant. This result is typical of what might be expected and comparable to the level of linkage seen in a marine fish (Diplodus sargus) which shows up to $11 \%$ linkage between locus pairs within a cohort even one year after recruitment (Planes \& Lenfant 2002). I therefore suggest that the signal of null alleles, and that of population expansion are both artifacts and a direct consequence of the magnitude of differential reproductive success. The high levels of linkage support this conclusion, and whilst population expansion or contraction are not excluded, traditional means of their calculation are in this case confounded with other demographic dynamics.

While I attribute much of the current genetic distribution pattern to spatial variation in fecundity, it is possible that population size fluctuations have played an important role. Most likely, the observed patterns are at least partly the result of the combined effects of population size fluctuations, loci with low to intermediate mutation rates, and low to intermediate levels of dispersal. Homoplasy is a common problem associated with microsatellite analyses, where alleles may be identical in state yet not identical by descent (Estoup et al. 2002). Traditionally, homoplasy is thought to be more evident for loci with high mutation rates (Estoup et al. 2002). When combined with population size fluctuations, loci with high mutation rates might be able to retain a signal of population structure due to new mutations occurring subsequent to population bottleneck events. Loci with lower mutation rates may be more susceptible to increased homoplasy, which may artificially lead to the inference of high levels of gene flow in the event of frequent population size fluctuations. Given lower levels of allelic diversity at these loci, the potential for the same alleles to become fixed by chance in different subpopulations during population crashes is greater than with higher levels of allelic diversity. This would explain the observed inference of high levels of gene flow in population genetic studies of cyclical species.

One of the motivating factors for a population genetic study on G. postica was the potential to guide the initiatives of the African Wild Silk Industry in southern Africa. In terms of the sustainable harvesting of moths my results therefore indicate that harvesting at a spatial scale of less than $50 \mathrm{~km}$ is likely to be offset by immigration of moths from surrounding areas. Harvesting over larger areas are therefore likely to diminish the probability of re-establishment of moths in the harvested area. Secondly, destructive harvesting is likely to have an effect on the genetic composition of moth populations up to 50-90 km away due to the disruption of natural dispersal patterns. The caveat to these conclusions is that there is likely to be more limited dispersal of female moths than is the case for males, due to their differences in wing loading, therefore having the effect of reducing the above spatial estimates. In addition, it is unlikely that outbreaks of moths in widely separated geographical areas ( $>100 \mathrm{~km}$ apart) are triggered by longdistance movements of females. Detailed knowledge of the dispersal ability of G. postica is crucial for the understanding of population cycles in this species, since it determines whether the species will persist in all regions given recent population crashes. The ability for relict populations to reseed regions where the species has declined determines the long-term sustainability of the species and thus the long-term sustainability of a harvesting programme. Inference of this ability from spatial population genetic data, however, is problematic as a result of unstable population dynamics.

\section{ACKNOWLEDGEMENTS}

This work was funded by the Mellon Foundation Grant to the Ph.D. project of W. Delport, and by a National Research Foundation grant. The opinions and views presented in this article are not necessarily those of the National Research Foundation. I would like to acknowledge the early stage contributions of Willem Ferguson and Paulette Bloomer and am grateful to T. Hoareau for valuable insights and constructive comments.

\section{REFERENCES}

ARNAUD-HAOND, S. \& BELKHIR K. 2007. Genclone: a computer program to analyse genotypic data, test for clonality and describe spatial clonal organisation. Molecular Ecology Notes 7: 15-17.

BECK, J. \& KITCHING, I.J. 2007. Correlates of range size and dispersal ability: a comparative analysis of sphingid moths from the Indo-Australian tropics. Gobal Ecology and Biogeography 16: 341-349.

BELKHIR, K., BORSA, P., CHIKHI, L., RAUFASTE, N. \& Bonhomme, F. 2004. GENETIX 4.05, Logiciel Sous Windows ${ }^{\mathrm{TM}}$ Pour la Génétique Des Populations. Laboratoire Génome Populations, Interactions. CNRS UMR 5000, Université de Montpellier II, Montpellier, France. 
BERTHIER. K., CHARBONNEL, N., GALAN, M., CHAVAL, Y. \& COSSON, J-F. 2005. Migration and recovery of the genetic diversity during the increasing density phase in cyclic vole populations. Molecular Ecology 15: 2665-2676.

BJORNSTAD, O.N., PELTONEN, M., LIEBHOLD, A.M. \& BALSTENSWEILER, W. 2002. Waves of larch budmoth outbreaks in the European Alps. Science 298: 1020-1023.

BLACK, W.C. \& KRAFSUR, E.S. 1985. A FORTRAN program for the calculation and analysis of two-locus linkage disequilibrium coefficients. Theoretical and Applied Genetics 70: 491-496.

CASEY, T.M. \& JOOS, B.A. 1983. Morphometrics, conductance, thoracic temperature, and flight energetics of noctuid and geometrid moths. Physiological Zoology 56: 160-173.

DAKIN, E.E. \& AVISE, J.C. 2004. Microsatellite null alleles in parentage analysis. Heredity 93.5: 504-509.

DELPORT, W. 2005. Temporal and spatial distribution of African wild silk moth, Gonometa postica, eruptions in southern Africa. Chapter 2. In: Population genetic inference of demographic processes in the African wild silk moth, Gonometa postica (Lasiocampidae). Ph.D. thesis, University of Pretoria, Pretoria, South Africa.

DELPORT, W., FERGUSON, J.W.H. \& BLOOMER, P 2005. Characterisation of six microsatellite loci in the African wild silk moth (Gonometa postica, Lasiocampidae. Molecular Ecology Notes 5: 860-862.

DINIZ-FILHO, J.A.F. \& TELLES, M.P.C. 2002 Spatial autocorrelation analysis and the identification of operational units for conservation in continuous populations. Conservation Biology 16: 924-935.

EPPERSON, B.K. 1995. Spatial distributions of genotypes under isolation by distance. Genetics 140 : 1431-1440.

EPPERSON, B.K. \& LI, T. 1996. Measurement of genetic structure within populations using Moran's spatial autocorrelation statistics. Proceedings of the National Acadademy of Sciences USA 93: 10528-10532.

ESTOUP, A., JARNE, P. \&, CORNUET, J-M. 2002. Homoplasy and mutation model at microsatellite loci and their consequences for population genetic analysis. Molecular Ecology 11: 1591-1604.

FENING, K.O., KIOKO, E.N., RAINA, S.K. \& MUEKE, J.M. 2008a. Monitoring wild silkmoth, Gonometa postica Walker, abundance, host plant diversity and distribution in Imba and Mumoni woodlands in Mwingi, Kenya. International Journal of Biodiversity Science and Management 4:104-111.

FENING, K.O., KIOKO, E.N., RAINA, S.K. \& MUEKE, M. 2008b. Parasitoids of the African wild silkmoth, Gonometa postica (Lepidoptera: Lasiocampidae) in the Mwingi forests, Kenya. Journal of Applied Entomology 133: 411-415.

FENSTER, C.B., VEKEMANS, X. \& HARDY, O.J. 2003. Quantifying gene flow from spatial genetic structure data in a metapopulation of Chamaecrista fasciculata (Leguminosae). Evolution 57: 995-1007.

GOUDET, J., DE MEEÜS, T., DAY, A.J. \& GLIDDON, C.J. 1994. The different levels of population structuring of the dogwhelk, Nucella lapillus, along the South Devon coast. In: Genetics and Evolution of Aquatic Organisms, (ed.) A.R. Beaumont, pp. 81-95. Chapman and Hall, London.

HABER, W.A. \& FRANKIE, G.W. 1989. A tropical hawkmoth community: Costa Rican dry forest Sphingidae. Biotropica 21: 155-172.

HARDY, O.J. \& VEKEMANS, X. 1999. Isolation by distance in a continuous population: reconciliation between spatial autocorrelation analysis and population genetics models. Heredity 83: 145-154.

HARDY, O.J. \& VEKEMANS, X. 2002. SPAGeDi: a versatile computer program to analyse spatial genetic structure at the individual or population levels. Molecular Ecology Notes 2: 618-620.

HARDY, O.J. \& VEKEMANS, X. 2003. SPAGeDi 1.1: a Program for Spatial Pattern Analysis of Genetic Diversity, User's manual. Online at: http://www.ebe.ulb.ac.be/ ebe/SPAGeDi_files/Manual_SPAGeDi\%20_1-4.pdf'

HARTLAND-ROWE, R. 1992 The Biology of the wild silkmoth Gonometa rufobrunnea Aurivillius (Lasiocampidae) in northeastern Botswana, with some comments on its potential as a source of wild silk. Botswana Notes and Records 24: 123-133.

IBRAHIM, K.M. 2001 Plague dynamics and population genetics of the desert locust: can turnover during recession maintain population genetic structure. Molecular Ecology 10: 581-591.

KALINOWSKI, S.T. \& TAPER, M.L. 2006. Maximum likelihood estimation of the frequency of null alleles at microsatellite loci. Conservation Genetics 7: 991-995.

KAPELLER, S., SCHROEDER, H. \& SCHUELER, S. 2011. Modelling the spatial population dynamics of the green oak leaf roller (Tortrix viridana) using density dependent competitive interactions: effects of herbivore mortality and varying host-plant quality. Ecological Modelling 222(7): 1293-1302.

LOISELLE, B.A., SORK, V.L., NASON, J. \& GRAHAM, C. 1995. Spatial genetic structure of tropical understory shrub, Psychotria officinalis (Rubiaceae). American Journal of Botany 82: 1420-1425.

MATTHEWS, P. 1992 (ed.). The Guinness Book of Records: 1993. New York.

McGEOCH, M.A., VELDTMAN, R. \& SCHOLTZ, C.H. 2004. Feasibility of annual cocoon yield requirements. Report to Wild Silk Africa. University of Stellenbosch, South Africa.

NGOKA, B.M., KIOKO, E.N., RAINA,S.K., MUEKE, J.M. \& KIMBU, D.M. 2007. Semi-captive rearing of the African wild silkmoth Gonometa postica (Lepidoptera: Lasiocampidae) on an indigenous and a non-indigenous host plant in Kenya. International Journal of Tropical Insect Science 27: 183-190.

ORSINI, L., CORANDER, J., ALASENTIE, A. \& HANSKI, I. 2008. Genetic spatial structure in a butterfly metapopulation correlates better with past than present demographic structure. Molecular Ecology 17: 2629-2642.

PLANES, S. \& LENFANT, P. 2002. Temporal change in the genetic structure between and within cohorts of a marine fish, Diplodus sargus, induced by a large variance in individual reproductive success. Molecular Ecology 11: 1515-1524.

RASBAND, W.S. 1997. Image J, U.S. National Institutes of Health, Bethesda, Maryland, U.S.A. Online at: http://rsb.info.nih.gov/ij/ 
RITLAND, K. 1996. Estimators for pairwise relatedness and individual inbreeding coefficients. Genetical Research Cambridge 67: 175-185.

ROUSSET, F. 1997. Genetic differentiation and estimation of gene flow from $F$-statistics under isolation by distance. Genetics 145: 1219-1228.

ROUSSET, F. 2000. Genetic differentiation between individuals. Journal of Evolutionary Biology 13: 58-62.

ROUSSET, F. 2008. genepop'007: a complete re-implementation of the genepop software for Windows and Linux. Molecular Ecology Resources 8: 103-106.

ROUSSET, F. \& RAYMOND, M. 1995. Testing heterozygote excess and deficiency. Genetics 140: 14131419.

RYDELL, J., SKALS, N., SURLYKKE, A. \& SVENSSON, M. 1997. Hearing and bat defence in geometrid winter moths. Proceedings of the Royal Society of London B Biology 264: 83-88.

RYDELL, J. \& LANCASTER, W.C. 2000. Flight and thermoregulation in moths were shaped by predation from bats. Oikos 88: 13-18.

SLATKIN, M. 1993. Isolation by distance in equilibrium and nonequilibrium populations. Evolution 47: 264-279.

SLATKIN, M. \& ARTER, H.E. 1991. Spatial autocorrelation methods in population genetics. American Naturalist 138: 498-517.

SOKAL, R.R., ODEN, N.L. 1978. Spatial autocorrelation in biology. 1. Methodology. Biological Journal of the Linnaean Society 10: 199-228.

SOKAL, R.R. \& WARTENBERG, D.E. 1983. A test of spatial autocorrelation analysis using an isolation by distance model. Genetics 105: 219-237.

STEYN, H.J.H. \& OLIVIER, Y. 2010. The evaluation of hydrogen peroxide bleaching of Gonometa postica silk. Journal of Family Ecology and Consumer Sciences 38: 84-91.

STEVENSON, R.D, CORBO, K., BACA, L.B. \& LE, Q.D. 1995. Cage size and flight speed of the tobacco hawkmoth Manduca sexta. Journal of Experimental Biology 198: $1665-1672$.
TURCHIN, P. 2003. Complex Population Dynamics: a Theoretical/Empirical Synthesis. Princeton Monographs in Population Biology. Princeton University Press, Princeton.

VELDTMAN, R. 2004 The ecology of southern African wild silk moths (Gonometa species, Lepidoptera: Lasiocampidae): consequences for their sustainable use. Ph.D. thesis, University of Pretoria, Pretoria.

VELDTMAN, R. \& McGEOCH, M.A. 2004. Spatially explicit analyses unveil density dependence. Proceedings of the Royal Society London B Biology 271: 2439-2444.

VELDTMAN, R. \& McGEOCH, M.A. \& SCHOLTZ, C.H. 2002. Variability in cocoon size in southern African wild silk moths: implications for sustainable harvesting. African Entomology 10: 127-136.

VELDTMAN, R. \& McGEOCH, M.A. \& SCHOLTZ, C.H. 2004. The parasitoids of southern African wild silkmoths (Lepidoptera). African Entomology 12: 117-122.

WAHLUND, S 1928. Zusammensetzung von Populationen und Korrelation-serscheinungen von Standpunkt der Verebungslehre aus betrachtet. Hereditas 11: 65-106.

WALDBAUER, G.P. \& STERNBURG, J.G. 1982. Long mating flights by Hyalophora cecropia. Journal of the Lepidoptera Society 36: 154-155.

WEIR, B.S. \& COCKERHAM, C.C. 1984. Estimating F-statistics for the analysis of population structure. Evolution 38: 1358-1370.

WHITLOCK, M.C. \& McCAULEY D.E. 1990. Some population genetic consequences of colony formation and extinction: genetic correlations with founding groups. Evolution 44: 1717-1724

WRIGHT, S. 1940. Breeding structure of populations in relation to speciation. American Naturalist 74: 232-248.

WRIGHT, S. 1969. Evolution and the Genetics of Populations. Vol. 2. The Theory of Gene Frequencies. University of Chicago Press, Chicago.

WRIGHT, S. 1943. Isolation by distance. Genetics 28: 114-138.

Responsible Editor: S. Willows-Munro
Appendix 1. Population-based locality information.

\begin{tabular}{lrr}
\hline Identifier & Latitude & Longitude \\
\hline pop01 & -29.09859 & 24.595197, \\
pop01 & -29.09859 & 24.595197, \\
pop01 & -29.09859 & 24.595197, \\
pop01 & -29.09859 & 24.595197, \\
pop01 & -29.09859 & 24.595197, \\
pop02 & -29.10386 & 24.592767, \\
pop02 & -29.10386 & 24.592767, \\
pop02 & -29.10386 & 24.592767 \\
pop03 & -28.57442 & 24.295616 \\
pop03 & -28.57442 & 24.295616, \\
pop03 & -28.57442 & 24.295616, \\
pop03 & -28.57442 & 24.295616, \\
pop04 & -28.57447 & 24.295058, \\
pop04 & -28.57447 & 24.295058, \\
pop04 & -28.57447 & 24.295058, \\
pop04 & -28.57447 & 24.295058, \\
pop05 & -29.12737 & 23.720368,
\end{tabular}

\begin{tabular}{lll}
\hline Identifier & Latitude & Longitude \\
\hline pop09 & -28.97023 & 22.012439, \\
pop09 & -28.97023 & 22.012439, \\
pop09 & -28.97023 & 22.012439, \\
pop09 & -28.97023 & 22.012439, \\
pop09 & -28.97023 & 22.012439, \\
pop09 & -28.97023 & 22.012439, \\
pop09 & -28.97023 & 22.012439, \\
pop10 & -29.09041 & 19.509584, \\
pop10 & -29.09041 & 19.509584, \\
pop10 & -29.09041 & 19.509584, \\
pop10 & -29.09041 & 19.509584, \\
pop10 & -29.09041 & 19.509584, \\
pop10 & -29.09041 & 19.509584, \\
pop11 & -28.84669 & 20.194137, \\
pop11 & -28.84669 & 20.194137, \\
pop11 & -28.84669 & 20.194137, \\
pop11 & -28.84669 & 20.194137,
\end{tabular}

Continued on p. 105 


\begin{tabular}{|c|c|c|}
\hline Identifier & Latitude & Longitude \\
\hline pop11 & -28.84669 & 20.194137, \\
\hline pop11 & -28.84669 & 20.194137, \\
\hline pop12 & -28.06313 & 18.816222, \\
\hline pop12 & -28.06313 & 18.816222, \\
\hline pop12 & -28.06313 & 18.816222, \\
\hline pop12 & -28.06313 & 18.816222, \\
\hline pop13 & -28.19843 & 22.11432, \\
\hline pop13 & -28.19843 & 22.11432, \\
\hline pop13 & -28.19843 & 22.11432, \\
\hline pop13 & -28.19843 & 22.11432, \\
\hline pop13 & -28.19843 & 22.11432, \\
\hline pop13 & -28.19843 & 22.11432, \\
\hline pop13 & -28.19843 & 22.11432, \\
\hline pop14 & -27.80659 & 22.022004, \\
\hline pop14 & -27.80659 & 22.022004, \\
\hline pop14 & -27.80659 & 22.022004, \\
\hline pop14 & -27.80659 & 22.022004 , \\
\hline pop14 & -27.80659 & 22.022004 , \\
\hline pop14 & -27.80659 & 22.022004 , \\
\hline pop14 & -27.80659 & 22.022004, \\
\hline pop15 & -27.67655 & 21.721414, \\
\hline pop15 & -27.67655 & 21.721414, \\
\hline pop15 & -27.67655 & 21.721414, \\
\hline pop15 & -27.67655 & 21.721414, \\
\hline pop15 & -27.67655 & 21.721414, \\
\hline pop16 & -27.58541 & 21.677157, \\
\hline pop16 & -27.58541 & 21.677157, \\
\hline pop16 & -27.58541 & 21.677157, \\
\hline pop16 & -27.58541 & 21.677157, \\
\hline pop16 & -27.58541 & 21.677157, \\
\hline pop17 & -27.23141 & 21.406909, \\
\hline pop17 & -27.23141 & 21.406909, \\
\hline pop17 & -27.23141 & 9009 , \\
\hline pop17 & -27.23141 & 21.406909, \\
\hline pop17 & -27.23141 & 21.406909, \\
\hline pop17 & -27.23141 & 21.406909, \\
\hline pop17 & -27.23141 & 21.406909, \\
\hline pop18 & -27.04133 & 21.50676 \\
\hline pop18 & -27.04133 & 21.50676, \\
\hline pop18 & -27.04133 & 21.50676, \\
\hline pop18 & -27.04133 & 21.50676, \\
\hline pop19 & -28.01831 & 21.449089, \\
\hline pop19 & -28.01831 & 21.449089, \\
\hline pop19 & -28.01831 & 21.449089, \\
\hline pop19 & -28.01831 & 21.449089, \\
\hline pop19 & -28.01831 & 21.449089, \\
\hline pop19 & -28.01831 & 21.449089, \\
\hline pop19 & -28.01831 & 21.449089, \\
\hline pop19 & -28.01831 & 21.449089, \\
\hline pop20 & -27.50728 & 20.314976, \\
\hline pop20 & -27.50728 & 20.314976, \\
\hline pop20 & -27.50728 & 20.314976, \\
\hline pop20 & -27.50728 & 20.314976, \\
\hline pop20 & -27.50728 & 20.314976, \\
\hline pop21 & -26.70701 & 24.321472, \\
\hline pop21 & -26.70701 & 24.321472, \\
\hline pop21 & -26.70701 & 24.321472, \\
\hline pop21 & -26.70701 & 24.321472, \\
\hline pop21 & -26.70707 & 24.321172, \\
\hline pop21 & -26.70707 & 24.321172, \\
\hline pop22 & -27.26000 & 23.050000 \\
\hline pop22 & -27.26000 & 23.050000 \\
\hline pop22 & -27.26000 & 23.050000 \\
\hline pop22 & -27.26000 & 23.050000 \\
\hline pop22 & -27.26000 & 23.050000 \\
\hline
\end{tabular}

\begin{tabular}{|c|c|c|}
\hline Identifier & Latitude & Longitude \\
\hline pp22 & -27.26000 & 23.050000 \\
\hline p22 & -27.26000 & 23.050000 \\
\hline p23 & -26.82064 & 22.82064, \\
\hline p23 & -26.82064 & 22.82064, \\
\hline p23 & -26.82064 & 22.82064, \\
\hline p24 & -26.66593 & 22.719222, \\
\hline p24 & -26.66593 & 22.719222, \\
\hline p24 & -26.66593 & 22.719222, \\
\hline p24 & -26.66593 & 22.719222, \\
\hline p24 & -26.66593 & 22.719222, \\
\hline p24 & -26.66593 & 22.719222, \\
\hline pop25 & -27.30147 & 22.448013, \\
\hline pop25 & -27.30147 & 22.448013, \\
\hline pop25 & -27.30147 & 22.448013, \\
\hline op25 & -27.30147 & 22.448013, \\
\hline p25 & -27.30147 & 22.448013, \\
\hline p26 & -24.62000 & 25. \\
\hline p26 & -24.62000 & 25.77000, \\
\hline p26 & -24.62000 & 25.7 \\
\hline p27 & -22.65916 & 21.9 \\
\hline op27 & -22.65916 & 21.927944, \\
\hline pp27 & -22.65916 & 944, \\
\hline pop27 & -22.65916 & 21.927944, \\
\hline pop27 & -22.65916 & 21.927944, \\
\hline pop27 & -22.65916 & 21.927944, \\
\hline pop27 & -22.65916 & 21.927944, \\
\hline pp27 & -22.6 & 7944, \\
\hline pop28 & -25.02697 & 18.885214, \\
\hline p28 & -25.0 & 18.8 \\
\hline p28 & -25.0 & 18.8 \\
\hline pop28 & -25.02697 & 18.8 \\
\hline pop29 & -24.1591 & 991, \\
\hline pop29 & -24.1591 & 18.849991, \\
\hline pop29 & -24.1591 & 18.849991, \\
\hline pop29 & -24.1591 & 18.849991, \\
\hline рор30 & -24.17564 & 18.765163, \\
\hline pop30 & -24.17564 & 18.765163, \\
\hline рор30 & -24.17564 & 18.765163, \\
\hline pop31 & -23.99672 & 18.959125, \\
\hline pop31 & -23.99672 & 18.959125, \\
\hline pp31 & -23.99672 & 18.959125, \\
\hline pop32 & -23.47184 & 18.728042, \\
\hline pop32 & -23.47184 & 18.728042, \\
\hline pop32 & -23.47184 & 18.728042, \\
\hline рор32 & -23.47184 & 18.728042, \\
\hline pop32 & -23.47184 & 18.728042, \\
\hline pop32 & -23.47184 & 18.728042, \\
\hline pop32 & -23.47184 & 18.728042, \\
\hline pop32 & -23.47184 & 18.728042, \\
\hline pop33 & -23.49683 & 18.426749, \\
\hline pop33 & -23.49683 & 18.426749, \\
\hline pop33 & -23.49683 & 18.426749, \\
\hline pop33 & -23.49683 & 18.426749, \\
\hline
\end{tabular}

\section{All sampled individuals}

$\begin{array}{lll}1, & -29.09859 & 24.595197 \\ 2, & -29.09859 & 24.595197 \\ 3, & -29.09859 & 24.595197 \\ 4, & -29.09859 & 24.595197 \\ 5, & -29.09859 & 24.595197 \\ 6, & -29.10386 & 24.592767 \\ 7, & -29.10386 & 24.592767 \\ 8, & -29.10386 & 24.592767 \\ 9, & -29.12737 & 23.720368 \\ 10, & -29.12737 & 23.720368\end{array}$

\begin{tabular}{|c|c|c|}
\hline Identifier & Latitude & Longitude \\
\hline 11, & -29.12737 & 23.720368 \\
\hline 12 & -29.12737 & 23.720368 \\
\hline 13, & -29.12637 & 23.721258 \\
\hline 14 & -29.12637 & 23.721258 \\
\hline 15, & -29.12637 & 23.721258 \\
\hline 16 & -29.12637 & 23.721258 \\
\hline 17, & -29.12637 & 23.721258 \\
\hline 18 & -29.12637 & 23.721258 \\
\hline 19, & -29.12637 & 23.721258 \\
\hline 20 & -28.57311 & 24.294183 \\
\hline 21 & -28.57311 & 24.294183 \\
\hline 22 & -28.57442 & 24.295616 \\
\hline 23 & -28.57442 & 24.295616 \\
\hline 24 & -28.57442 & 24.295616 \\
\hline 25 & -28.57442 & 5616 \\
\hline 26 & -28.57397 & 24.295444 \\
\hline 27 & -28.57447 & 24.295058 \\
\hline 28 & -28.57447 & 24.295058 \\
\hline 29 , & -28.57447 & 24.295058 \\
\hline 30 & -28.57447 & 24.295058 \\
\hline 31, & -28.57445 & 24.295868 \\
\hline 32, & -28.57445 & 24.295868 \\
\hline 33 & -26.70701 & 24.321472 \\
\hline 34 & -26.70701 & 24.321472 \\
\hline 35, & -26.70701 & 24.321472 \\
\hline 36 & -26.70701 & 24.321472 \\
\hline 37 & -26.70707 & 24.321172 \\
\hline 38, & -26.70707 & 24.321172 \\
\hline 39, & -26.66593 & 22.719222 \\
\hline 40 & -26.66593 & 22.719222 \\
\hline 41, & -26.66593 & 22.719222 \\
\hline 42 & -26.66593 & 22.719222 \\
\hline 43 & -26.66593 & 22.719222 \\
\hline 44, & -26.66593 & 22.719222 \\
\hline 45, & -26.99267 & 23.812228 \\
\hline 46 & -27.21501 & 24.106826 \\
\hline 47 & -27.26997 & 24.1484 \\
\hline 48 & -27.26997 & 24.1484 \\
\hline 49 & -27.53881 & 23.217861 \\
\hline 50 & -27.53881 & 23.217861 \\
\hline 51 & -27.30147 & 22.448013 \\
\hline 52 & -27.30147 & 22.448013 \\
\hline 53 & -27.30147 & 22.448013 \\
\hline 54, & $-27.3^{3}$ & 22.448013 \\
\hline 55 & -27.30147 & 22.448013 \\
\hline 56 & -27.30193 & 22.45106 \\
\hline 57 & -27.29979 & 22.448791 \\
\hline 58 & -27.29752 & 22.449135 \\
\hline 59, & -27.29672 & 22.449387 \\
\hline 60 & -27.29532 & 22.449548 \\
\hline 61, & -27.29532 & 22.449548 \\
\hline 62 & -27.29356 & 22.450358 \\
\hline 63 & -27.29314 & 22.449628 \\
\hline 64 & -27.29429 & 22.34168 \\
\hline 65, & -27.29385 & 22.342678 \\
\hline 66 & -27.32 & 22.329787 \\
\hline 67 & -27.30714 & 22.32563 \\
\hline 68 & -26.94458 & 22.108167 \\
\hline 69 & -26.94458 & 22.108167 \\
\hline 70 & -27.23141 & 21.406909 \\
\hline 71, & -27.23141 & 21.406909 \\
\hline 72 & -27.23141 & 21.406909 \\
\hline 73, & -27.23141 & 21.406909 \\
\hline 74 & -27.56906 & 21.665479 \\
\hline 75 , & -27.56906 & 21.665479 \\
\hline
\end{tabular}




\begin{tabular}{lrl}
\hline Identifier & Latitude & Longitude \\
\hline 76, & -27.58541 & 21.677157 \\
77, & -27.58541 & 21.677157 \\
78, & -27.58541 & 21.677157 \\
79, & -27.58541 & 21.677157 \\
80, & -27.58541 & 21.677157 \\
81, & -27.67655 & 21.721414 \\
82, & -27.67655 & 21.721414 \\
83, & -27.67655 & 21.721414 \\
84, & -27.67655 & 21.721414 \\
85, & -27.67655 & 21.721414 \\
86, & -27.80659 & 22.022004 \\
87, & -27.80659 & 22.022004 \\
88, & -27.80659 & 22.022004 \\
89, & -27.80659 & 22.022004 \\
90, & -27.80659 & 22.022004 \\
91, & -27.80659 & 22.022004 \\
92, & -27.80659 & 22.022004 \\
93, & -28.19843 & 22.11432 \\
94, & -28.19843 & 22.11432 \\
95, & -28.19843 & 22.11432 \\
96, & -28.19843 & 22.11432 \\
97, & -28.19843 & 22.11432 \\
98, & -28.19843 & 22.11432 \\
99, & -28.19843 & 22.11432 \\
100, & -28.01831 & 21.449089 \\
101, & -28.01831 & 21.449089 \\
102, & -28.01831 & 21.449089 \\
103, & -28.01831 & 21.449089 \\
104, & -28.01831 & 21.449089 \\
105, & -28.01831 & 21.449089 \\
106, & -28.01831 & 21.449089 \\
107, & -28.01831 & 21.449089 \\
108, & -27.50728 & 20.314976 \\
109, & -27.50728 & 20.314976 \\
110, & -27.50728 & 20.314976 \\
123, & -29.21097 & 22.066319 \\
111, & -27.50728 & 20.314976 \\
112, & -27.50728 & 20.314976 \\
113, & -28.49322 & 21.181448 \\
114, & -28.49322 & 21.181448 \\
115, & -28.97023 & 22.012439 \\
116, & -28.97023 & 22.012439 \\
117, & -28.97023 & 22.012439 \\
118, & -28.97023 & 22.012439 \\
& -28.97023 & 22.012439 \\
\hline 190 & -28.97023 & 22.012439 \\
\hline 12.09 & 22.066319
\end{tabular}

\begin{tabular}{lll}
\hline Identifier & Latitude & Longitude \\
\hline 124, & -29.21097 & 22.066319 \\
125, & -29.21097 & 22.066319 \\
126, & -28.84669 & 20.194137 \\
127, & -28.84669 & 20.194137 \\
128, & -28.84669 & 20.194137 \\
129, & -28.84669 & 20.194137 \\
130, & -28.84669 & 20.194137 \\
131, & -28.84669 & 20.194137 \\
132, & -29.09041 & 19.509584 \\
133, & -29.09041 & 19.509584 \\
134, & -29.09041 & 19.509584 \\
135, & -29.09041 & 19.509584 \\
136, & -29.09041 & 19.509584 \\
137, & -29.09041 & 19.509584 \\
138, & -28.06313 & 18.816222 \\
139, & -28.06313 & 18.816222 \\
140, & -28.06313 & 18.816222 \\
141, & -28.06313 & 18.816222 \\
142, & -26.28313 & 18.63278 \\
143, & -25.4955 & 19.302254 \\
144, & -25.27392 & 19.075645 \\
145, & -25.02697 & 18.885214 \\
146, & -25.02697 & 18.885214 \\
147, & -25.02697 & 18.885214 \\
148, & -25.02697 & 18.885214 \\
149, & -24.17564 & 18.765163 \\
150, & -24.17564 & 18.765163 \\
151, & -24.17564 & 18.765163 \\
152, & -24.1591 & 18.849991 \\
153, & -24.1591 & 18.849991 \\
154, & -24.1591 & 18.849991 \\
155, & -24.1591 & 18.849991 \\
156, & -23.99672 & 18.959125 \\
157, & -23.99672 & 18.959125 \\
158, & -23.99672 & 18.959125 \\
159, & -23.47184 & 18.728042 \\
160, & -23.47184 & 18.728042 \\
161, & -23.47184 & 18.728042 \\
162, & -23.47184 & 18.728042 \\
163, & -23.47184 & 18.728042 \\
164, & -23.47184 & 18.728042 \\
165, & -23.47184 & 18.728042 \\
166, & -23.47184 & 18.728042 \\
167, & -23.49683 & 18.426749 \\
168, & -23.49683 & 18.426749 \\
169, & -23.49683 & 18.426749 \\
171, & -23.49683 & 18.426749 \\
& -22.10699 & 20.53179 \\
\hline
\end{tabular}

\begin{tabular}{lll}
\hline Identifier & \multicolumn{1}{c}{ Latitude } & Longitude \\
\hline 172, & -22.10699 & 20.53179 \\
173, & -22.65916 & 21.927944 \\
174,1 & -22.65916 & 21.927944 \\
175, & -22.65916 & 21.927944 \\
176, & -22.65916 & 21.927944 \\
177, & -22.65916 & 21.927944 \\
178, & -22.65916 & 21.927944 \\
179, & -22.65916 & 21.927944 \\
180, & -22.65916 & 21.927944 \\
181, & -24.49832 & 23.91699 \\
$182, \mathrm{~b}$ & -27.04133 & 21.50676 \\
$183, \mathrm{f}$ & -27.23141 & 21.406909 \\
$184, \mathrm{~m}$ & -27.23141 & 21.406909 \\
$185, \mathrm{~m}$ & -27.23141 & 21.406909 \\
186,2 & -27.04133 & 21.50676 \\
187,3 & -27.04133 & 21.50676 \\
188,4 & -27.04133 & 21.50676 \\
189,6 & -27.04133 & 21.50676 \\
190, & -28.57445 & 24.295868 \\
191, & -26.72126 & 22.829338 \\
192, & -28.7 & 24.9833 \\
193, & -28.7 & 24.9833 \\
194, & -24.62 & 25.77 \\
195, & -26.26551 & 20.10946 \\
196, & -26.57489 & 20.61161 \\
197, & -27.06271 & 21.15465 \\
198, & -26.82064 & 22.82064 \\
199, & -26.82064 & 22.82064 \\
200, & -26.82064 & 22.82064 \\
201, & -27.0425 & 20.7775 \\
202, & -24.62 & 25.77 \\
203, & -24.62 & 25.77 \\
204, & -24.62 & 25.77 \\
205, & -24.64 & 25.67 \\
206, & -27.26 & 23.05 \\
207, & -27.26 & 23.05 \\
208, & -27.26 & 23.05 \\
209, & -27.26 & 23.05 \\
210, & -27.26 & 23.05 \\
211, & -27.26 & 23.05 \\
212, & -27.26 & 23.05 \\
213, & -24.52 & 25.81 \\
214, & -24.15 & 25.41 \\
215, & -24.15 & 25.41 \\
216, & -27.69227 & 23.531862 \\
217, & -27.69227 & 23.531862 \\
218, & -28.6 & 22.55 \\
219, & -28.6 & 22.55 \\
220, & -28.6 & 22.55 \\
\hline & & \\
19
\end{tabular}

